Original paper

\title{
Efficiency of personal dosimetry methods in vascular interventional radiology
}

\author{
Fernando Antonio Bacchim Neto ${ }^{\mathrm{a}}$, Allan Felipe Fattori Alves ${ }^{\mathrm{a}}$, Yvone Maria Mascarenhas ${ }^{\mathrm{b}}$, \\ Guilherme Giacomini ${ }^{\mathrm{a}}$, Nadine Helena Pelegrino Bastos Maués ${ }^{\mathrm{a}}$, Patrícia Nicolucci ${ }^{\mathrm{c}}$, \\ Carlos Clayton Macedo de Freitas ${ }^{\mathrm{d}}$, Matheus Alvarez ${ }^{\mathrm{e}}$, Diana Rodrigues de Pina ${ }^{\mathrm{f}, *}$
}

\footnotetext{
${ }^{a}$ São Paulo State University (UNESP), Instituto de Biociências de Botucatu, Departamento de Física e Biofísica, Botucatu 18618-000, São Paulo, Brazil

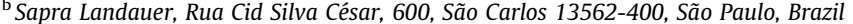

' Universidade de São Paulo (USP), Faculdade de Filosofia, Ciências e Letras de Ribeirão Preto, Centro de Instrumentação, Dosimetria e Radioproteção (CIDRA), Av. Bandeirantes,

3900 Bairro Monte Alegre, Ribeirão Preto 14040-901, São Paulo, Brazil

${ }^{\mathrm{d}}$ São Paulo State University (UNESP), Faculdade de Medicina de Botucatu, Departamento de Neurologia, Psicologia e Psiquiatria, Botucatu 18618-000, São Paulo, Brazil

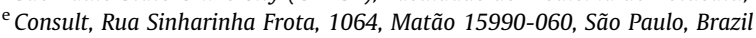

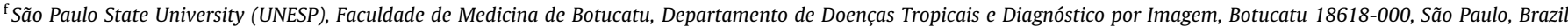

\section{A R T I C L E I N F O}

\section{Article history:}

Received 30 January 2017

Received in Revised form 3 April 2017

Accepted 11 April 2017

Available online 24 April 2017

\section{Keywords:}

Effective dose

Personal dosimetry

Interventional radiology

Anthropomorphic phantom

\begin{abstract}
A B S T R A C T
Purpose: The aim of the present study was to determine the efficiency of six methods for calculate the effective dose $(E)$ that is received by health professionals during vascular interventional procedures. Methods: We evaluated the efficiency of six methods that are currently used to estimate professionals' $E$, based on national and international recommendations for interventional radiology. Equivalent doses on the head, neck, chest, abdomen, feet, and hands of seven professionals were monitored during 50 vascular interventional radiology procedures. Professionals' $E$ was calculated for each procedure according to six methods that are commonly employed internationally. To determine the best method, a more efficient $E$ calculation method was used to determine the reference value (reference $E$ ) for comparison.

Results: The highest equivalent dose were found for the hands $(0.34 \pm 0.93 \mathrm{mSv})$. The two methods that are described by Brazilian regulations overestimated $E$ by approximately $100 \%$ and $200 \%$. The more efficient method was the one that is recommended by the United States National Council on Radiological Protection and Measurements (NCRP). The mean and median differences of this method relative to reference $E$ were close to $0 \%$, and its standard deviation was the lowest among the six methods.

Conclusions: The present study showed that the most precise method was the one that is recommended by the NCRP, which uses two dosimeters (one over and one under protective aprons). The use of methods that employ at least two dosimeters are more efficient and provide better information regarding estimates of $E$ and doses for shielded and unshielded regions.
\end{abstract}

๑) 2017 Associazione Italiana di Fisica Medica. Published by Elsevier Ltd. All rights reserved.

\section{Introduction}

Physicians who perform interventional X-ray procedures are exposed to the highest radiation doses compared with all other health professionals [1]. Several studies have shown that such

\footnotetext{
* Corresponding author at: Departamento de Doenças Tropicais e Diagnóstico por Imagem, Faculdade de Medicina de Botucatu - FMB, Universidade Estadual Paulista "Júlio de Mesquita Filho" - UNESP, P.O. BOX 576, 18618-000 Botucatu, São Paulo, Brazil.

E-mail addresses: bacchim@ibb.unesp.br (F.A. Bacchim Neto), allan@ibb.unesp. br (A.F.F. Alves),yvone@sapra.com.br (Y.M. Mascarenhas), giacomini@ibb.unesp.br (G. Giacomini), nadine.maues@gmail.com (Nadine Helena Pelegrino Bastos Maués), nicol@usp.br (P. Nicolucci), cclayton@fmb.unesp.br (C.C.M. de Freitas), matheus@ ibb.unesp.br (M. Alvarez), drpina@fmb.unesp.br (D.R.d. Pina).
}

physicians are exposed to non-uniform radiation levels throughout their bodies during interventional procedures [2-4].

The effective dose $(E)$ is a physical quantity that is used to measure the detriment that is caused by radiation in the human body, thus providing important information for radiological protection purposes. The $E$ value depends on equivalent doses that are measured in different organs and tissues of the body, which are usually the most sensitive to stochastic effect induction [5]. During each procedure, professionals use a personal dosimeter on the chest or abdomen to estimate the $E$ that is received [5].

Different methods are used to estimate $E$ during interventional procedures [6]. In Europe, a single personal dosimeter that is positioned on the anterior chest below the radiological protective apron was previously considered a good estimate of $E[5,6]$. 
However, this approach does not provide any information regarding unshielded regions of the professionals' body [5,6].

In the United States, the National Council on Radiological Protection and Measurements (NCRP) recommends the use of two personal dosimeters, one over and one under the radiological protective apron [7]. The dosimeter over the apron may be positioned on the neck [7], and the dosimeter under the apron may be placed on the chest or abdomen [7].

In Brazil, the Agência Nacional de Vigilância Sanitária (ANVISA) recommends the use of a single dosimeter over the protective apron. This dosimeter should be positioned on the torso region that is most exposed to radiation [8].

During interventional procedures, professionals are exposed to non-uniform radiation fields that are indicated by different absorbed doses throughout tissues and organs. Thus, a precise calculation of $E$ is a major concern for radiation protection purposes $[4,5]$. However, to our knowledge, no studies have properly assessed the efficiency of several different methods that are used to calculate professionals' $E$. These different methods can either underestimate or overestimate the correct value of $E[2,4]$.

The aim of the present study was to evaluate the efficiency of six methods that are used internationally to calculate the $E$ that is received by health professionals in interventional radiology procedures. We also determine the best method for measuring the $E$ that is received by health professionals during vascular interventional procedures.

\section{Methods}

The present study involved three main steps (Fig. 1). The first step consisted of a complete dosimetry assessment of seven physicians during 50 vascular interventional radiology procedures. Equivalent incident doses on the head, neck, chest, abdomen, feet, and hands were monitored (described in Section 2.1).

After monitoring the radiation doses in step 1, step 2 consisted of calculating $E$ according to six different methodologies (described in Section 2.2).

To assess the efficiency of all six methods, a more accurate reference method was employed. For the reference method, correlation factors ( $C F s$ ) were calculated between external and internal doses using an anthropomorphic phantom. Twenty-four internal organs and tissues were assessed according to the International Commission on Radiological Protection (ICRP) for $E$ calculations [5]. After applying the CFs to the external doses that were monitored for each professional, the $E$ was calculated for each procedure (described in Section 2.3).

All six estimated values of $E$ that were obtained in step 2 were compared with the reference $E$ of step 3, which allowed us to assess the efficiency of each procedure compared with the reference values.

These three steps were applied to 50 procedures that were performed in the Botucatu Medical School, São Paulo State University, Brazil. The procedures were performed using LCV Plus equipment (Advantx General Electric Medical Systems, Milwaukee, WI, USA). The equipment complied with all standard quality control tests. Lead blades were placed underneath the patient table for stationary shielding. Ceiling-suspended transparent shielding and a patient dosimeter were not used.

\subsection{Dosimetry measurements for professionals during clinical practice}

The physicians who conducted interventional vascular procedures were monitored for dosimetry assessment. Incident doses for different body regions of the professional were monitored using dosimeters during each procedure. Seven professionals who per- formed the 50 procedures were monitored. During all of the procedures, the physician remained approximately $0.5 \mathrm{~m}$ from the imaged patient.

Thermoluminescent dosimeters (TLDs; TLD-100; LiF: Mg, Ti Harshaw, Solon, OH, USA) were used for dose measurements. The pellets were square shaped with dimensions of $3.2 \times 3.2 \times 0.9 \mathrm{~mm}^{3}$. Dosimeters were positioned on the head (top of the surgical mask), neck, chest, abdomen, feet, and hands (wrists) of the professionals, over the radiological protective aprons. All of the monitored professionals used radiological protective aprons, such as lead aprons, thyroid shields, and lead glasses. The protective aprons (Kiran, Nerul, Navi Mumbai, 400706, India), i.e. lead aprons and thyroid shields, were $0.5 \mathrm{~mm}$ lead-equivalent for exposition in X-ray fields produced with a range of 50 to $150 \mathrm{kVp}$. For each evaluated region, three dosimeters were used for a more accurate dose measurement [4].

For each procedure, a control group of three TLDs was used outside of controlled areas to monitor background radiation. Background measurements were subtracted from the professionals' dosimeter readings.

According to the current legislation in our country, the dosimeters were calibrated in Photon Dose Equivalent $\mathrm{Hx}$ (measured in Sv) using a known dose level ( $1 \mathrm{mGy}$ ). The calibration was performed using a Co-60 radiation source on a $4 \pi$ geometry free air exposure using a $3 \mathrm{~mm}$ Lucite ${ }^{\circledR}$ build up plate. The mean ratio between the reading dose (nanoCoulombs) and equivalent dose (milliSievert) for each dosimeter was used as an individual calibration factor. The uncertainty of a single dose measurement was 5.37\%. This uncertainty value is dependent of uncertainty in the calibration process, dose reading and uncertainty of control dose subtracted.

The procedure modalities that were monitored included lower limb and abdominal angiographies (20), lower limb and abdominal percutaneous transluminal angioplasty (15), and abdominal aortic aneurysm treatment with stent graft placement (15). These procedures were performed between 75 and $85 \mathrm{kVp}$, with automatic $\mathrm{mA}$ control, 1.9-3.8 frames/s, "medium" noise level, and $32 \mathrm{~cm}$ field of view.

\subsection{Other methodologies to estimate the professionals' effective dose}

After the dosimetry step, the $E$ value was estimated according to six different methodologies. These estimates were performed for each professional who was monitored and compared with the reference $E$ which is calculated using clinical and anthropomorphic phantom dosimetry.

In Brazil, regulations require that $E$ is calculated with a dosimeter positioned at the most exposed torso region, over the protective apron. Dosimeter readings were corrected by a factor of 0.1 according to this normative guideline [8].

The dosimeter is usually used on the chest, without prior assessment of the most exposed region. The first two methods that were used to estimate $E$ and compared with the reference $E$ were based on Brazilian legislation:

- Method 1: Chest dose over protective aprons, corrected by a factor of 0.1 ;

- Method 2: Abdominal dose over protective aprons, corrected by a factor of 0.1 .

In The United States, the NCRP recommends combining readings from the neck dosimeter outside the protective apron (indicating unshielded head doses) and readings from the abdomen (waist height) or chest measured inside the protective apron using Eq. (1) $[6,7]$ :

$\mathrm{E}_{\mathrm{NCRP}}($ estimate $)=0.5 \mathrm{H}_{\mathrm{IN}}+0.025 \mathrm{H}_{\mathrm{OUT}}$ 


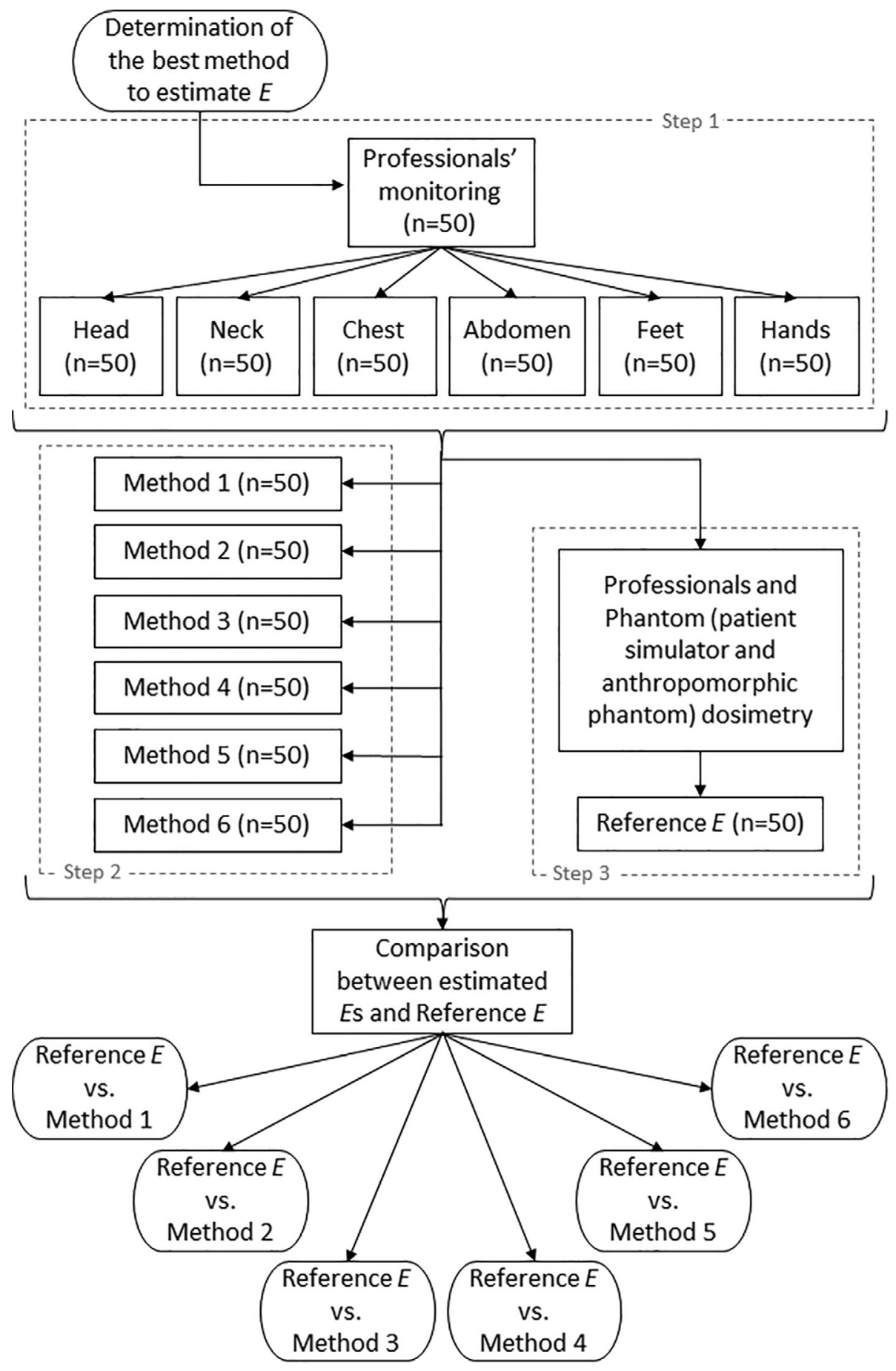

Fig. 1. Flowchart of the three steps that were performed and described in the Methods section.

The formula above was used to estimate Es for each procedure that was monitored, with two other methods that were based on North American legislation:

- Method 3: Neck unshielded dose for $\mathrm{H}_{\mathrm{OUT}}$ and chest shielded dose for $\mathrm{H}_{\mathrm{IN}}$;

- Method 4: Neck unshielded dose for $\mathrm{H}_{\mathrm{OUT}}$ and abdomen shielded dose for $\mathrm{H}_{\mathrm{IN}}$.

For shielded regions, the incident dose under radiological protection was obtained using the outside protective apron dose multiplied by a factor of 0.05 [9]. This transmission value was confirmed by experimental measurements with an ionization chamber in a radiation field produced with $85 \mathrm{kVp}$ and scattered by a patient-equivalent phantom.

In Europe, the use of one dosimeter on the anterior chest, under the protective apron, was previously assumed to be a good estimate of the operator's $E$ according to Miller et al. [6]. Although a single dosimeter under protective aprons does not provide any information about unshielded regions, estimates of $E$ were performed using two other methods:

- Method 5: Chest dose corrected by an attenuation factor of 0.05 ; 
- Method 6: Abdomen dose corrected by an attenuation factor of 0.05 .

The efficiency of these six methods was assessed by comparing each procedure with the reference $E$ (described in Section 2.3).

\subsection{Reference effective doses and correlation factors between external and internal doses}

A patient-equivalent phantom that consisted of a $30 \times 30 \times 30$ $\mathrm{cm} 3$ acrylic cube was used to simulate scattered radiation in patients during interventional procedures [10]. The Alderson RANDO anthropomorphic phantom (model ART-200, RSD Phantoms, Long Beach, CA, USA) was placed approximately $0.5 \mathrm{~m}$ from the patient-equivalent phantom in the left side of the equipment. The anthropomorphic phantom angular position was the typical position occupied by the physician in the routine practice. This phantom was positioned so that the imaged region of the patient-equivalent phantom was approximately $45^{\circ}$ to its anteroposterior axis. Thus, the radiation scattered by the patient reached the phantom in the middle angle between its frontal and lateral surface. This setup simulates scattered radiation that is received by the physician's body. The Alderson RANDO represents a man that is $175 \mathrm{~cm}$ tall and weighs $73.5 \mathrm{~kg}$. The radiological protection apparatus was maintained similarly to clinical conditions, with the exception of plumber glasses (i.e., the lead apron and thyroid shield were positioned on the anthropomorphic phantom).

Table 1

Position and number of TLDs in the anthropomorphic phantom.

\begin{tabular}{|c|c|c|c|}
\hline $\begin{array}{l}\text { External } \\
\text { dosimeters }\end{array}$ & $\begin{array}{l}\text { Number of } \\
\text { dosimeters }\end{array}$ & Internal organ or tissue monitored & $\begin{array}{l}\text { Number of } \\
\text { dosimeters }\end{array}$ \\
\hline \multirow[t]{3}{*}{ Head } & \multirow[t]{3}{*}{3} & Oral mucosa & 3 \\
\hline & & Brain & 3 \\
\hline & & Salivary glands (right and left sides) & 6 \\
\hline Neck & 3 & Thyroid & 3 \\
\hline \multirow[t]{12}{*}{ Chest } & \multirow[t]{12}{*}{3} & Esophagus (upper thoracic level) & 3 \\
\hline & & Esophagus (mid-thoracic level) & 3 \\
\hline & & Breast (right and left sides) & 6 \\
\hline & & $\begin{array}{l}\text { Lung (upper thoracic level, right } \\
\text { and left sides) }\end{array}$ & 6 \\
\hline & & $\begin{array}{l}\text { Lung (mid-thoracic level, right and } \\
\text { left sides) }\end{array}$ & 6 \\
\hline & & $\begin{array}{l}\text { Lung (lower thoracic level, right and } \\
\text { left sides) }\end{array}$ & 6 \\
\hline & & Heart & 3 \\
\hline & & Bone marrow (thoracic spine) & 3 \\
\hline & & $\begin{array}{l}\text { Bone marrow (ribs, right and left } \\
\text { sides) }\end{array}$ & 6 \\
\hline & & Bone marrow (sternum) & 3 \\
\hline & & Thymus & 3 \\
\hline & & Extrathoracic region & 3 \\
\hline \multirow[t]{15}{*}{ Abdomen } & \multirow[t]{15}{*}{3} & Stomach & 3 \\
\hline & & Spleen & 3 \\
\hline & & Liver & 3 \\
\hline & & Pancreas & 3 \\
\hline & & Small intestine & 3 \\
\hline & & $\begin{array}{l}\text { Kidneys/adrenals (right and left } \\
\text { sides) }\end{array}$ & 6 \\
\hline & & Gall bladder & 3 \\
\hline & & $\begin{array}{l}\text { Bone marrow (right and left iliac } \\
\text { crest) }\end{array}$ & 6 \\
\hline & & Gonads (right and left ovaries) & 6 \\
\hline & & Bladder & 3 \\
\hline & & Uterus & 3 \\
\hline & & Prostate & 3 \\
\hline & & Gonads (testicles) & 3 \\
\hline & & $\begin{array}{l}\text { Bone marrow (right and left femoral } \\
\text { head) }\end{array}$ & 6 \\
\hline & & Colon & 3 \\
\hline
\end{tabular}

TLD sets with three dosimeters were positioned inside the anthropomorphic phantom in positions that corresponded to the main organs and tissues according to the ICRP [5] for the measurement of $E$ (Table 1 ). Columns show both the external and internal dosimeter positions and their corresponding numbers. Bone marrow was monitored in several positions that represented the regions of major tissue concentrations in an adult body [11].

Skin doses were estimated using the average doses on the surface of the head, neck, chest, abdomen, hands, and feet, under the protective apron. When one structure that was listed by the ICRP was monitored in different regions of the anthropomorphic phantom, the average dose was used for the calculation of $E$. Bilateral organs were monitored on both sides. The bone surface was not monitored because it accounts for only $1 \%$ of $E$.

The TLDs were also positioned on the surface of the anthropomorphic phantom in the same regions as the physician's chest, abdomen, neck, and head, over the protection. Dosimeters for background measurements were also used, and their readings were subtracted from all of the measured doses.

The CFs were determined by dividing the external dose by the internal dose for each monitored region (i.e., incident dose for each organ within the chest divided by the incident dose on the chest; incident dose for each organ within the abdomen divided by the incident dose on the abdomen). Some internal structures that were listed by the ICRP were present in more than one region (e.g., bone marrow); therefore, these structures present one $C F$ for each region.

All of the above procedures were repeated for 75 and $85 \mathrm{kVp}$, three times for each $\mathrm{kVp}$. All of the other parameters were maintained: automatic mA control, 1.9-3.8 frames/s, "medium" noise level, and $32 \mathrm{~cm}$ field of view.

After applying the CFs, the absorbed doses for 24 internal organs were determined for each monitored procedure. The Es were calculated for each procedure as the sum of the internal organ or tissue absorbed doses multiplied by individual tissue weighting factors according to the ICRP [5].

\subsection{Statistical analysis}

The statistical analysis was performed using MINITAB 14 software (Minitab, State College, PA, USA). Mean CF values that were obtained for each structure for 75 and $85 \mathrm{kVp}$ were compared using the Wilcoxon test and linear regression plots. The estimates that were obtained for the six methods were compared with reference $E$ using Bland Altman plots for mean differences [12]. The difference (\%) refers to the $E$ that was obtained from the tested methods minus the reference $E$, divided by reference $E$. Differences were calculated for each procedure.

\section{Results}

Incident doses on the head, neck, chest, abdomen, feet, and hands for seven health professionals who conducted 50 interventional vascular radiology procedures were monitored. The mean \pm standard deviation $(S D)$ of the fluoroscopy time was $13.2 \pm 10.3 \mathrm{~min}$. Partial body doses for the professionals' dosimetry are summarized in Table 2.

Significant differences between left and right side organs were found. On average, the internal organs or structures positioned on the interventionist left side were exposed $26 \%$ more when compared to the right side. The highest observed difference was for breast, where the left breast received, on average, $45 \%$ more radiation than the right breast.

The uncertainty values presented in Table 2 for CFs of each internal organ or structures resulted from total dosimetry and cal- 
Table 2

Partial body equivalent doses for professionals' dosimetry. The data are expressed as the mean, $S D$, median, and interquartile range $(I R)$ of equivalent doses for all monitored regions.

\begin{tabular}{lll}
\hline & Mean $\pm S D(\mu S v)$ & Median $(I R)(\mu S v)$ \\
\hline Head & $70.7 \pm 101.7$ & $39.4(10.3-79.9)$ \\
Neck & $71.7 \pm 93.9$ & $44.3(11.5-87.4)$ \\
Chest & $82.9 \pm 114.6$ & $42.0(13.5-95.8)$ \\
Abdomen & $151.3 \pm 248.8$ & $58.3(14.7-176.2)$ \\
Feet & $219.1 \pm 438.4$ & $67.9(16.8-166.0)$ \\
Hands & $340.0 \pm 936.0$ & $59.7(19.7-175.8)$ \\
\hline
\end{tabular}

culation uncertainties. Several uncertainties are considered to calculate theses values such as those related to dosimetry reading, skin and organ dose measurements, CFs averaging procedure and bilateral organs dose asymmetry. The highest equivalent doses were found for the hands $(340.0 \pm 936.0 \mu \mathrm{Sv})$, reaching a maximum of $5700 \mu \mathrm{Sv}$. The head received the lowest doses ( $70.7 \pm 101.7 \mu \mathrm{Sv})$. The average $C F$ s for each energy ( 75 and $85 \mathrm{kVp}$ ) and their standard deviation are summarized in Table 3. These factors were compared using the Wilcoxon test, and no significant difference was found $(p=0.07)$.

Fig. 2 shows the linear regression $C F$ values for 75 and $85 \mathrm{kVp}$. The linear regression was $\mathrm{y}=1.1 \mathrm{x}-0.0022$, with $R^{2}=0.98$.

The linear regressions for the 75 and $85 \mathrm{kVp} C F$ s indicated that the angular coefficient was close to 1 , and the linear coefficient was 0 . The $R^{2}$ approached 1 , and the relatively low standard deviation corroborated the Wilcoxon test results, in which no significant difference was found between these groups. Therefore, the average $C F$ s between the two energies was used to calculate the reference $E$ values.

Fig. 3 shows box plots for reference $E$ values that were calculated with the CFs and the six methods that were used to estimate the Es.

Bland Altman plots for the difference and average between reference $E$ and each estimate are shown in Figs. 4-6.
Bland Altman plots were used to compare the reference $E$ and the six methods to estimate Es that were received by the physicians. Methods 1 and 2 were the most conservative methodologies among the six evaluated, overestimating $E$ by an average of approximately $100 \%$ and $200 \%$, respectively. Based on our findings, the most precise methodologies were Methods 3, 4, and 5. These methods neither overestimated nor underestimated, on average, the professionals' $E$ by more than a few percent.

\section{Discussion}

The present study assessed partial body doses and Es received by health professionals using routine clinical dosimetry, which revealed the highest values for the hands. By associating clinical dosimetry with phantom measurements, the reference $E$ that was received by the professionals was calculated for each procedure. This last step allowed comparisons between reference $E$ and the estimated $E$ for each of the six different methods that are applied in different countries.

This comparison showed that Methods 1 and 2 overestimated $E$ by an average of approximately $100 \%$ and $200 \%$, respectively. Their standard deviations were extremely high and reached more than $200 \%$ for Method 2. However, these methodologies did not underestimate $E$ values more than the others. From a safety point of view, the overestimation that results from these methods can provide a safety margin for occupational exposure.

Methods 3, 4, and 5 presented mean and median differences that were close to $0 \%$, with low standard deviations. For radiological protection purposes, Method 5 was the least suitable for routine application because it does not use external dosimeters and does not account for unshielded regions. Method 6 overestimated the mean and median values of $E$, with up to $50 \%$ differences.

Method 4, which is recommended by the NCRP, was the most precise. Its mean and median differences relative to the reference $E$ were close to $0 \%$, with the lowest standard deviation among the six methods. For radiological protection purposes, it is the most

Table 3

Average CFs for 75 and $85 \mathrm{kVp}$. The data are expressed as the mean and SD of $C F$ s for each tissue or organ that was used to calculate the reference $E$.

\begin{tabular}{|c|c|c|c|c|c|}
\hline External dosimeters & Internal organs or tissues & $75 \mathrm{kVp} C F$ & $85 \mathrm{kVp} C F$ & Average $C F \pm \mathrm{SD}$ & Uncertainty (\%) \\
\hline \multirow[t]{3}{*}{ Head } & Oral mucosa & 0.243 & 0.284 & $0.264 \pm 0.029$ & 0.112 \\
\hline & Brain & 0.168 & 0.137 & $0.152 \pm 0.022$ & 0.159 \\
\hline & Salivary glands & 0.243 & 0.284 & $0.264 \pm 0.022$ & 0.145 \\
\hline Neck $^{*}$ & Thyroid & 0.032 & 0.028 & $0.030 \pm 0.003$ & 0.072 \\
\hline \multirow[t]{9}{*}{ Chest ${ }^{*}$} & Esophagus & 0.013 & 0.015 & $0.014 \pm 0.002$ & 0.146 \\
\hline & Breast & 0.049 & 0.050 & $0.049 \pm 0.001$ & 0.223 \\
\hline & Lung & 0.021 & 0.020 & $0.020 \pm 0.001$ & 0.155 \\
\hline & Heart & 0.021 & 0.020 & $0.021 \pm 0.001$ & 0.126 \\
\hline & Bone marrow (thoracic spine) & 0.014 & 0.013 & $0.013 \pm 0.001$ & 0.121 \\
\hline & Bone marrow (ribs) & 0.034 & 0.031 & $0.032 \pm 0.002$ & 0.194 \\
\hline & Bone marrow (sternum) & 0.035 & 0.035 & $0.035 \pm 0.000$ & 0.105 \\
\hline & Thymus & 0.033 & 0.032 & $0.032 \pm 0.000$ & 0.146 \\
\hline & Extrathoracic region & 0.050 & 0.049 & $0.049 \pm 0.000$ & 0.106 \\
\hline \multirow[t]{15}{*}{ Abdomen" } & Stomach & 0.035 & 0.036 & $0.036 \pm 0.001$ & 0.092 \\
\hline & Spleen & 0.017 & 0.017 & $0.017 \pm 0.000$ & 0.094 \\
\hline & Liver & 0.020 & 0.022 & $0.021 \pm 0.001$ & 0.110 \\
\hline & Pancreas & 0.012 & 0.012 & $0.012 \pm 0.000$ & 0.111 \\
\hline & Small intestine & 0.033 & 0.036 & $0.035 \pm 0.002$ & 0.110 \\
\hline & Kidneys/adrenals & 0.011 & 0.012 & $0.011 \pm 0.001$ & 0.129 \\
\hline & Gall bladder & 0.023 & 0.027 & $0.025 \pm 0.003$ & 0.073 \\
\hline & Bone marrow (right and left iliac crest) & 0.016 & 0.015 & $0.015 \pm 0.000$ & 0.163 \\
\hline & Gonads (ovaries) & 0.020 & 0.025 & $0.023 \pm 0.003$ & 0.139 \\
\hline & Bladder & 0.015 & 0.018 & $0.016 \pm 0.002$ & 0.128 \\
\hline & Uterus & 0.014 & 0.016 & $0.015 \pm 0.002$ & 0.071 \\
\hline & Prostate & 0.010 & 0.010 & $0.010 \pm 0.000$ & 0.091 \\
\hline & Gonads (testicles) & 0.046 & 0.049 & $0.048 \pm 0.002$ & 0.093 \\
\hline & Bone marrow (right and left femoral head) & 0.012 & 0.012 & $0.012 \pm 0.000$ & 0.163 \\
\hline & Colon & 0.013 & 0.015 & $0.014 \pm 0.001$ & 0.146 \\
\hline
\end{tabular}

External dosimeters positioned above radiological protective aprons. 


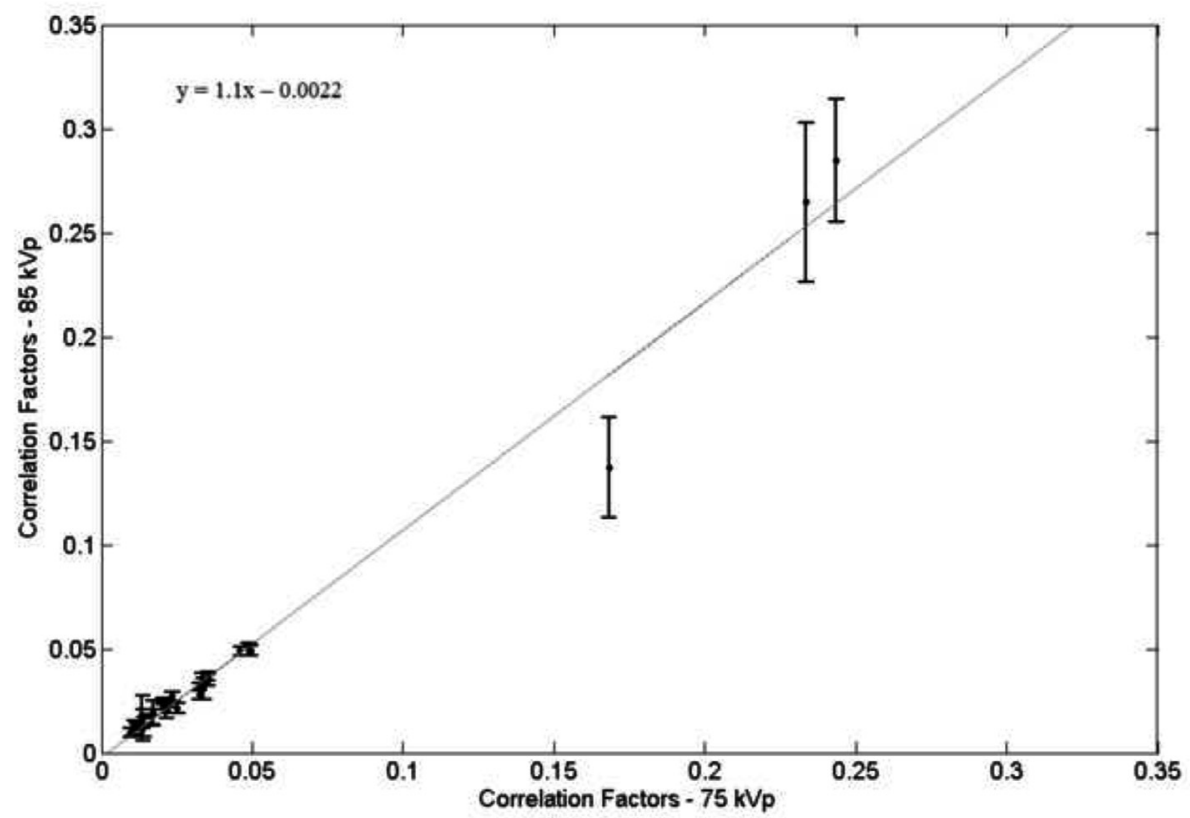

Fig. 2. Linear regression of $C F s$ measured for 75 and $85 \mathrm{kVp}$. The limits of uncertainty (in absolute values) calculated for each $C F$ are represented by error bars.

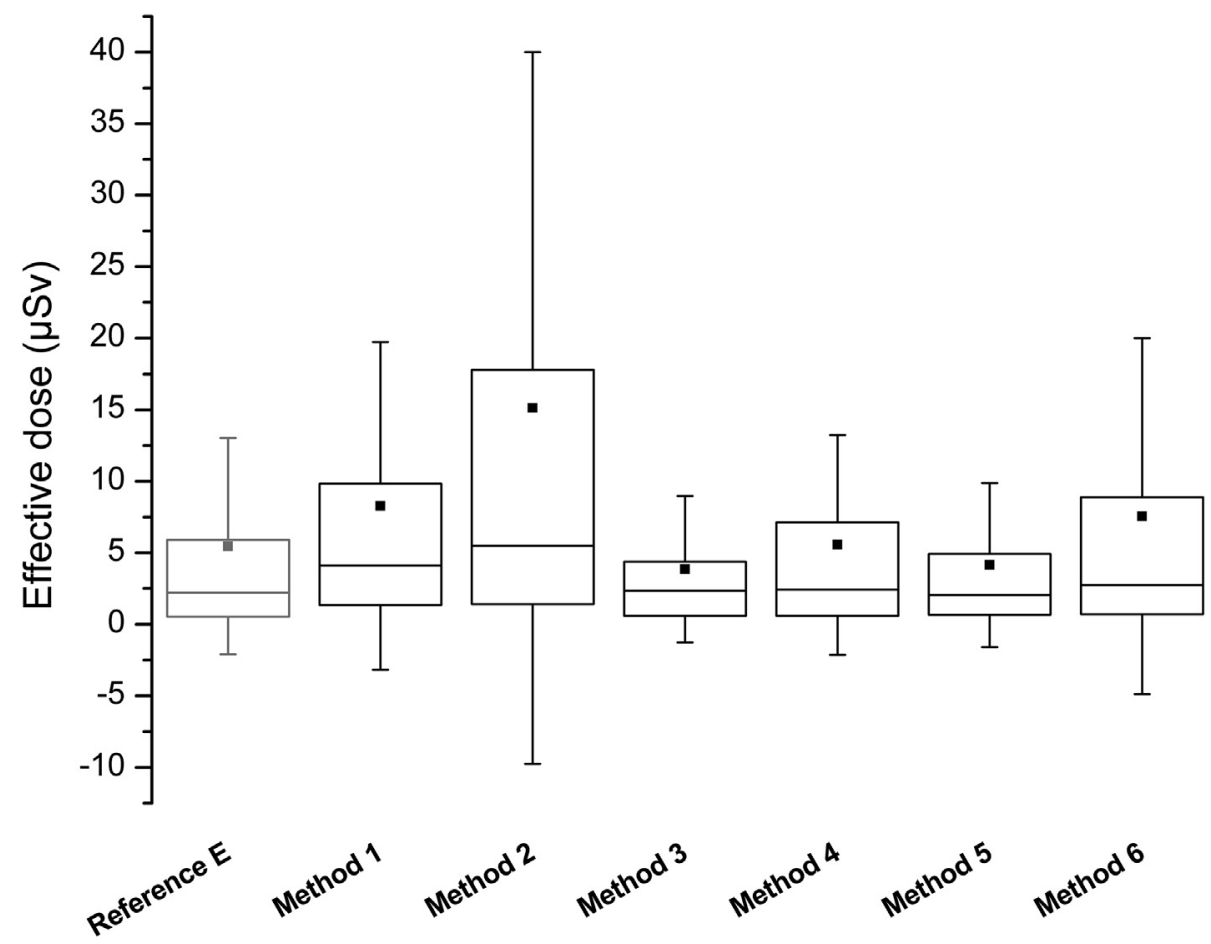

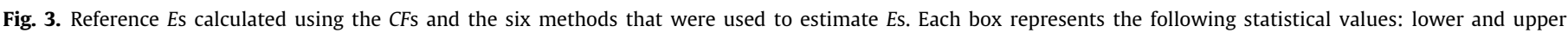

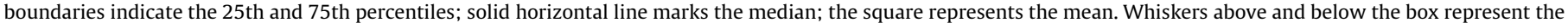
standard deviation.

adequate for monitoring interventional professionals because it considers doses both under and over radiological protective aprons.

There is another European method from Switzerland [13] to calculate effective doses from dosimeters placed both above and below radiological aprons through the following Equation: $\mathrm{Hp}$ $(10)=\mathrm{Hp}(10) \_$under $+\mathrm{a} * \mathrm{Hp}(10) \_$over. In this calculation, dosimeters doses measured under and above aprons are used, and also a correction factor $\mathrm{a}=0.05$. The equation results in the same equa- tion performed in Method 1 (Brazilian). This occurs since in our methodology the dose below the apron corresponds to the dose above the apron multiplied by the apron transmission factor (0.05). Thus, we find the same equations for the effective dose calculations in both methods and any inferred conclusion for the Method 1 also applies to the Swiss method.

Most of the present results were consistent with previous reports. Mean values of $70 \mu \mathrm{Sv}$ for the unshielded head and $40 \mu \mathrm{Sv}$ for the hands (wrists) were found, which are consistent 


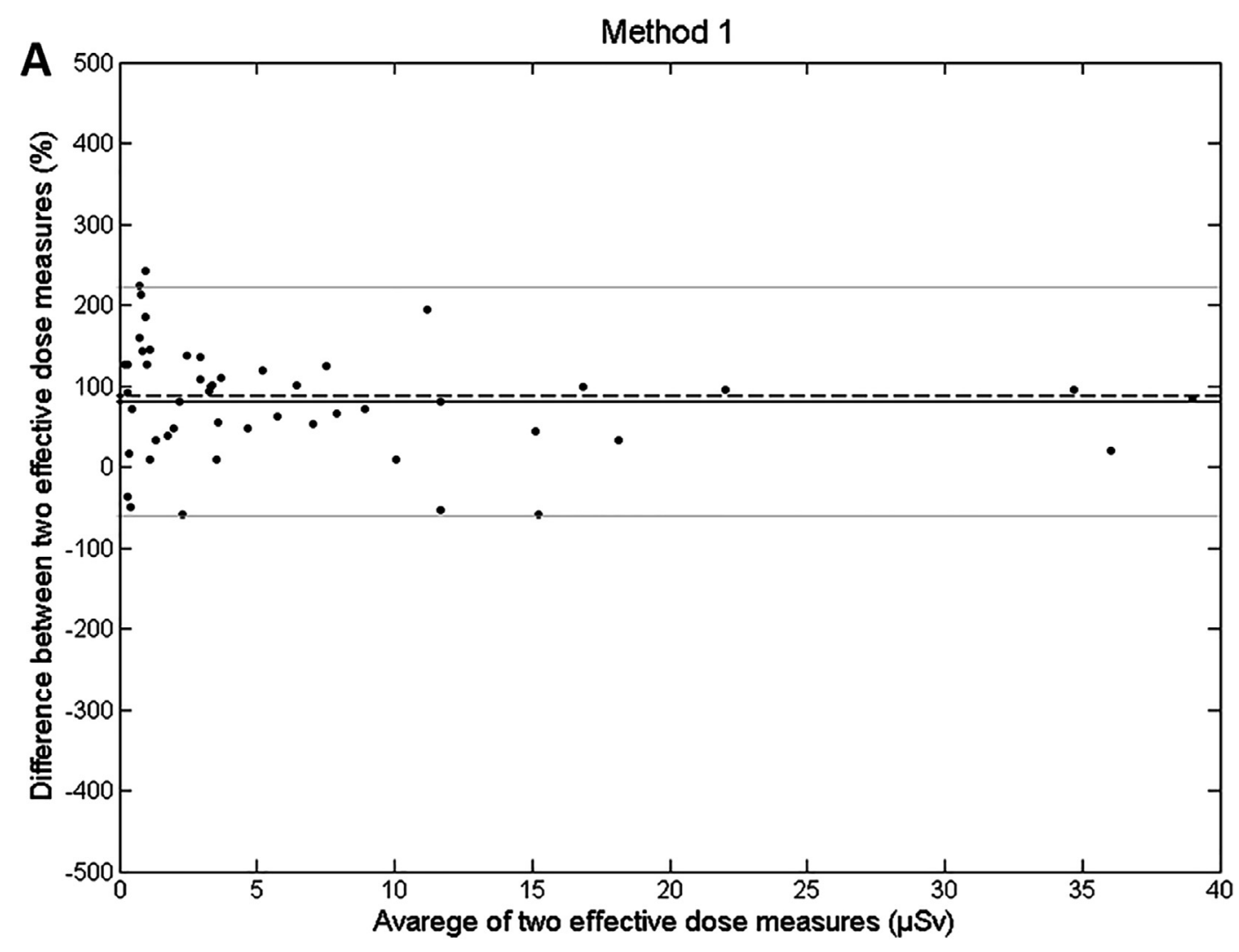

Method 2

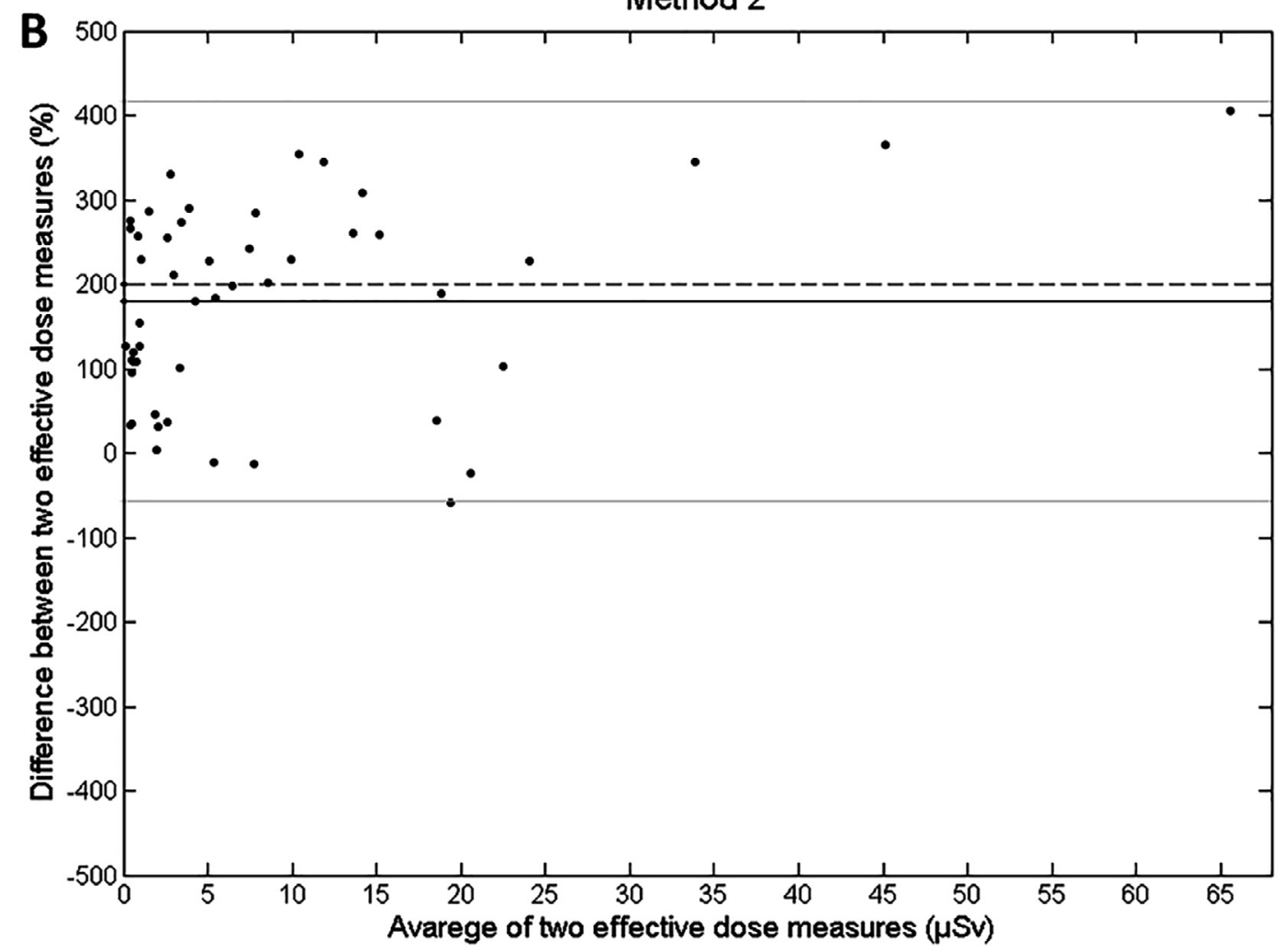

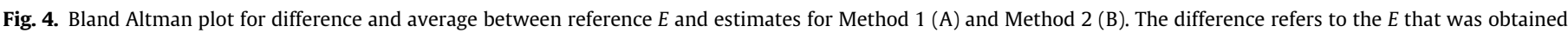

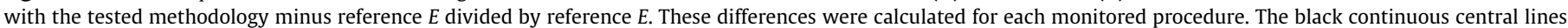

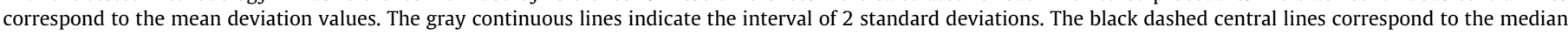
value of differences. 

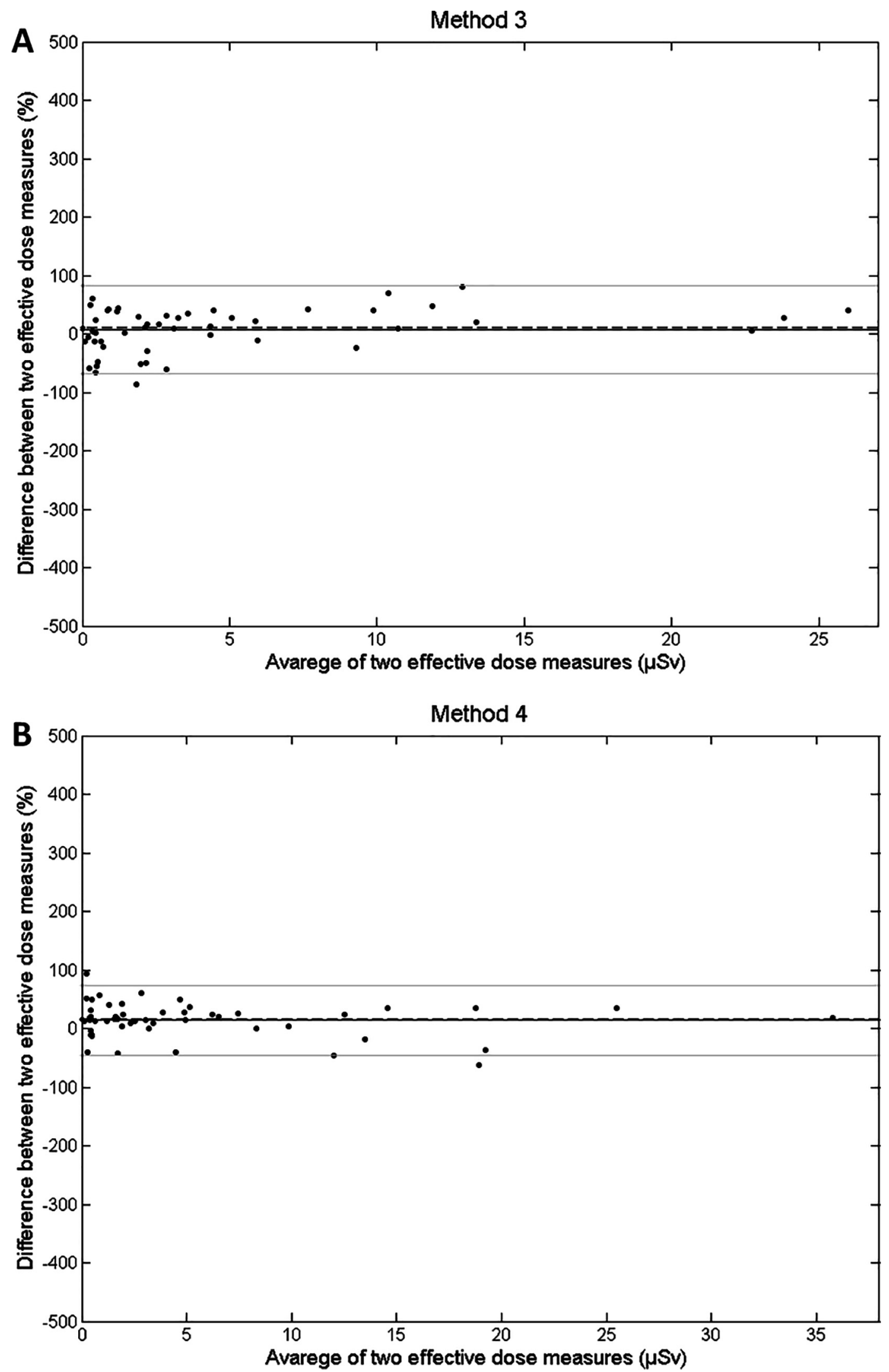

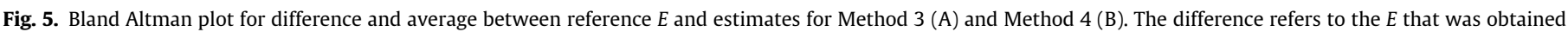

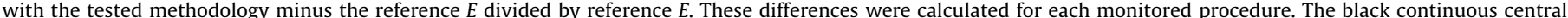

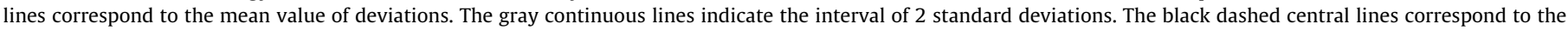
median value of differences. 

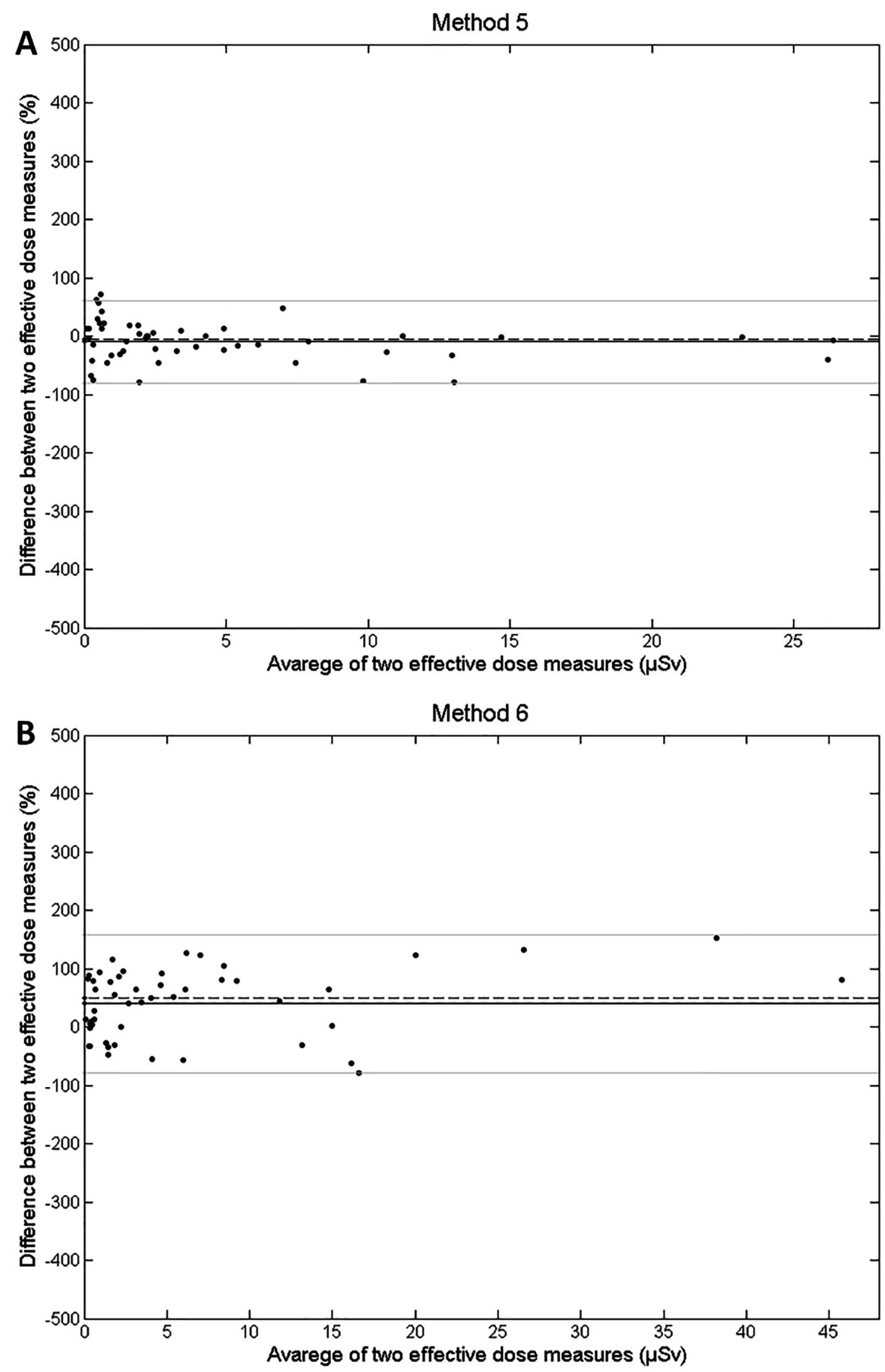

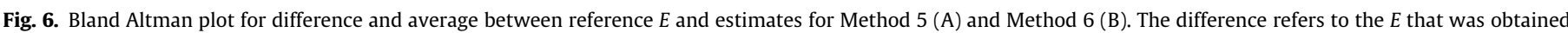

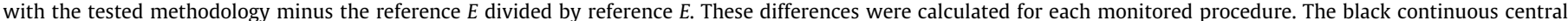

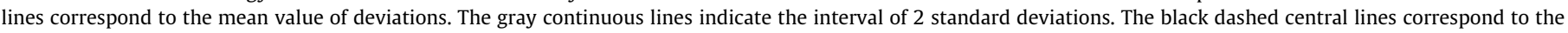
median value of differences. 
with Efstathopoulos et al. (2011) [14]. The mean doses for the unshielded chest were $80 \mu \mathrm{Sv}$ per procedure, which is nearly half of the values that were reported by Sailer et al. (2014) [15]. However, Sailer et al. (2014) used only half of the mean fluoroscopy time compared with the procedures reported herein [15]. For the unshielded neck, the mean value of $71 \mu \mathrm{Sv}$ that was observed in the present study was consistent with Delichas et al. (2003) [16].

Median doses of $42 \mu \mathrm{Sv}$ were measured over lead aprons on the chest, whereas Hausler et al. (2009) reported a median dose of $16 \mu \mathrm{Sv}$ [2]. This difference may be attributable to the use of a ceiling-suspended acrylic shield in the procedures that were monitored by Hausler.

In the present study, the health professionals' reference Es were calculated using clinical measurements and phantom CFs for each procedure. The median reference $E$ was $2.2 \mu \mathrm{Sv}$, which is in accordance with Hausler et al. [2].

The organs and tissues that contribute most to the $E$ parameter are located on the head, chest, and abdomen. Generally, personal dosimeters are used at chest height $[4,6]$. The median doses that were obtained for the chest and abdomen over protective aprons were 0.04 and $0.06 \mathrm{mSv}$, respectively. This difference indicates that the position of the dosimeter contributes significantly to the $E$ measurement. Thus, dosimeter positioning should be a major concern in an interventionist department.

The mean CFs that were found for $75 \mathrm{kVp}$ for each organ were compared with $85 \mathrm{kVp}$, and no significant differences were observed. This is also evident in the linear regression that is presented in Fig. 2 and its corresponding $R^{2}$ value. The linear regressions and $R^{2}$ values showed a strong association and low dispersion between CFs for 75 and $85 \mathrm{kVp}$. Therefore, the average $C F$ between the two energies were used for $E$ calculations.

Although the present study evaluated three of the more common procedures that are performed by hospital services, a substantial number of modalities should be monitored for a more complete assessment. The influence of stationary protection (and different configurations thereof) on $E$ should also be investigated.

Our calibration process used the quantity Photon Dose Equivalent (Hx), according to our current country normative. According to H. Stadtmann and C. Hranitzky, in diagnostic radiology energy ranges, doses measured in $\mathrm{Hx}$ are a good estimative for doses measured in $\mathrm{Hp}(0.07)[17,18]$.

\section{Conclusions}

The present study evaluated the efficiency of six different methodologies that are used to calculate Es for health professionals during interventional procedures. The most conservative method for $E$ estimation was the one that is recommended by Brazilian legislation, with a dosimeter positioned on the professionals' abdomen (Method 2). This method overestimated $E$ by an average of $200 \%$. However, it did not underestimate $E$ more than the other methods. Therefore, this method does not necessarily undermine the professionals' safety. The most accurate methodology was Method 4, which is used in the United States and recommended by the NCRP. This method did not overestimate the physician's $E$ by more than a few percent, and its standard deviation from the reference $E$ was the lowest. Therefore, this methodology, which employs at least two dosimeters (one over and one under the protective apron) is recommended. It provides a more precise calculation of $E$ and provides information about both shielded and unshielded regions. Additionally, in some situations in which the incident dose for the hands can be high, additional dosimeters for these regions are recommended.

\section{Acknowledgements}

The authors would like to thank all of the physicians at Botucatu Medical Hospital for their support and dedication throughout the study. The authors would also like to thank the Sapra Landauer (especially Ph.D. Maria de Fátima Magon) for their support throughout the study.

\section{References}

[1] Smilowitz NR, Balter S, Weisz G. Occupational hazards of interventional cardiology. Cardiovasc Revasc Med 2013;14(4):223-8.

[2] Hausler U, Czarwinski R, Brix G. Radiation exposure of medical staff from interventional X-ray procedures: a multicentre study. Eur Radiol 2009;19 (8):2000-8.

[3] Miller DL et al. Clinical radiation management for fluoroscopically guided interventional procedures. Radiology 2010;257(2):321-32.

[4] Bacchim Neto FA et al. Occupational radiation exposure in vascular interventional radiology: a complete evaluation of different body regions. Phys Med 2016;32(8):1019-24.

[5] International Commission on Radiological Protection. The 2007 Recommendations of the International Commission on Radiological Protection. ICRP publication 103. Ann ICRP 2007;37(2-4):1-332.

[6] Miller DL et al. Occupational radiation protection in interventional radiology: a joint guideline of the Cardiovascular and Interventional Radiology Society of Europe and the Society of Interventional Radiology. Cardiovasc Intervent Radiol 2010;33(2):230-9.

[7] National Council on Radiation Protection and Measurements, Use of personal monitors to estimate effective dose equivalent and effective dose to workers for external exposure to low-LET radiation: recommendations of the National Council on Radiation Protection and Measurements. Report no. 22. Bethesda, MD: National Council on Radiation Protection and Measurements; 1995.

[8] ANVISA, Portaria $N^{\circ} 453$. Aprova o regulamento técnico que estabelece as diretrizes básicas de proteção radiológica em radiodiagnóstico médico e odontológico. 1998, Diário Oficial da União: Agencia Nacional de Vigilância Sanitária.

[9] Christodoulou EG et al. Evaluation of the transmitted exposure through lead equivalent aprons used in a radiology department, including the contribution from backscatter. Med Phys 2003;30(6):1033-8.

[10] Chu RYL, Fisher J, Archer BR, Conway BJ, Goodsit MM. Standardized methods for measuring diagnostic X-ray exposures. New York: American Association of Physicists in Medicine by the American Institute of Physics; 1982.

[11] Cristy M. Active bone marrow distribution as a function of age in humans. Phys Med Biol 1981;26(3):389-400.

[12] Bland JM, Altman DG. Measuring agreement in method comparison studies. Stat Methods Med Res 1999;8(2):135-60.

[13] Ordonnance sur la dosimétrie individuelle, Le Département fédéral de l'intérieur et le Département fédéral de l'environnement, des transports, de l'énergie et de la communication; 2013. p. 68.

[14] Efstathopoulos EP et al. Occupational radiation doses to the extremities and the eyes in interventional radiology and cardiology procedures. Br J Radiol 2011;84(997):70-7.

[15] Sailer AM et al. Occupational radiation exposure during endovascular aortic repair. Cardiovasc Intervent Radiol 2015;38(4):827-32.

[16] Delichas $\mathrm{M}$ et al. Radiation exposure to cardiologists performing interventional cardiology procedures. Eur J Radiol 2003;48(3):268-73.

[17] Stadtmann H, Hranitzky C. Uncertainty assessment and comparison of different dose algorithms used to evaluate a two element LiF:Mg, Ti TL personal dosemeter. Austrian Research Centers GmbH; 2008.

[18] Stadtmann H, Hranitzky C. Comparison of different dose algorithms used to evaluate a two element LiF: Mg, Ti TL personal dosemeter. Radiat Meas 2008;43(2):571-5. 